\title{
Uninsured citizens in the period of the Greek economic crisis: Health, income, housing. The case of an Attica Region Municipality.
}

\author{
Spiros Koutavas' ${ }^{1}$, George Koulierakis ${ }^{2}$, Irini Zografaki ${ }^{3}$, Kalliopi Orfanaki ${ }^{4}$ \\ 1. RN, MSc, MPH, Department of Protection and Promotion of Public Health, Municipality of Korydallos, Korydallos, Greece \\ 2. Health Psychologist, PhD, Associate Professor, Department of Public Health Policy, University of West Attica', Athens, Greece \\ 3. Biologist, MPH, Department of Child Health, National School of Public Health, Athens, Greece \\ 4. Sociologist, PhD, Adjunct Professor, School of Social Sciences, Hellenic Open University, Patras, Greece
}

'As of 7th May 2019, the National School of Public Health was merged with the University of West Attica and operates as the Department of Public Health Policy.

\section{ABSTRACT}

Introduction: In Greece, the implementation of the Fiscal Adjustment Programs was combined with policies of economic austerity resulting in high levels of unemployment and exclusion from health insurance for a large proportion of the population.

Aim: This study explores the demographic and socio-economic characteristics and the health status of the uninsured citizens in one of the biggest Municipalities in Attica region. The study covers the period 2012-2016, during the economic crisis in Greece.

Methods: Data stemming from official documents, from individual files of 1,738 uninsured citizens were processed. Possible associations between population characteristics and chronic disease categories were examined, using the chi-square test and univariable/multivariable analysis for chronic disease as an outcome.

Results: Almost forty-two percent (41.7\%) of the study population suffered from a chronic disease; with the $48 \%$ of those patients having zero real annual income and $60.4 \%$ being hosted by a relative or an acquaintance. Of the sample diagnosed with a mental illness $71 \%$ lived as guests to friends or relatives. Diagnosis with cancer appeared to be more related to zero income, compared to other chronic disease categories $(72.7 \%, p<0.001)$. In the multivariable model, male gender ( $\mathrm{OR}=1.7095 \% \mathrm{Cl}: 1.35-2.13)$, age ( $\mathrm{OR}=1.0395 \% \mathrm{Cl}: 1.02-1.04)$ and guest status (OR=1.57 95\% Cl: 1.24-2.00) were associated with a chronic disease.

Conclusions: In Greece, in the midst of the economic crisis, uninsured citizens with chronic illness are called upon to manage their health problem with zero income and housing problems. A key strategy to address such a prospect of further health degradation of the particular population group can only be the strengthening and reorganization of the provision of social protection and health services around a primary care model developed and functioning at community level, with as its basic principle, universal and equal access to it, for all citizens.

Key-words: chronic disease, financial crisis, housing, income, uninsured citizens 


\section{HIGHLIGHTS/KEY POINTS}

- Austerity measures applied in Greece during the financial crisis have resulted in an increase in the proportion of uninsured citizens.

- The Greek economic crisis has affected vulnerable population groups at the community level in the local government.

- Uninsured citizens with chronic disease are called upon to manage their health problem in the midst of an economic crisis, with zero income and guests in relatives or acquaintances.

\section{INTRODUCTION}

M acroeconomic and social policies implemented in a country are among the structural social determinants of health (Solar \& Irwin 2010) and those related to health inequalities. The economic crisis seems to threaten mainly the low social strata and increases socio-economic inequalities and inequality in social protection and health (Kyriopoulos \& Tsiantou 2010). In Greece, the implementation of the Fiscal Adjustment Programs was combined with economic austerity policies, which together with the economic recession and rising of unemployment, led a significant part of the population out of the health insurance system and prevented them from equal access to health services.

The two-way relationship between an individual's financial situation and his/her level of health has been studied and confirmed by a number of researchers (Mackenbach 2005, Stuckler et al 2009), who concluded that people experiencing poverty and social exclusion are at multiple risk of suffering from serious illnesses or even dying from premature death.

The economic crisis and high unemployment are both related with a significant impact on the physical and mental health of the citizens (Marmot \& Bell 2009). On the one hand, the reduction of individual income and unemployment are associated with greater morbidity and less use of private health services (Economou et al 2014, Stuckler \& Basu 2014). On the other hand, curtailing public spending on health lowers the quantity offered and degrades the quality of the services concerned. Unemployment and low income, as shown by a series of recent studies in Greece (Institute of Social and Preventive Medicine 2016), are associated with mental disorders, drug addiction and substance use problems, poor quality of food, smoking, overuse of alcoholic beverages and an increase in chronic diseases.

Greece's 2008 entry into a fiscal adjustment program led to a sharp increase in unemployment: from $7.8 \%$ in 2008 to $27.5 \%$ in 2013 (Hellenic Statistical Authority -
HSA 2016). In addition, the implementation of the fiscal adjustment pact was accompanied by particularly negative social impacts, with the Poverty and Social Exclusion Index rising from $27.7 \%$ in 2010 to $35.7 \%$ in 2015 (Labor Institute of the Greek General Confederation of Labor 2017). Finally, Greece is ranked at the lowest $1 / 3$ compared to other countries of the OECD in the majority of the 25 criteria related to quality of life le.g. income, work, housing, health, education, security, etc.), and chronic morbidity rates have increased from $39.7 \%$ in 2009 , to $49.3 \%$ in 2014 (HSA 2016).

The impact of the economic crisis is also significant on Greek population's mental health. Research has recorded an increase in the proportion of people with symptoms of major depression (Kentikelenis et al 2014, Simou \& Koutsogeorgou 2014), while there was an increase in suicide incidents by $1 / 3$, associated with the austerity measures implemented in June 2011 under the first fiscal adjustment pact (Branas et al 2015). At the same time, potential long-term health effects of the economic crisis on the population can be foreseen when funding for prevention programs was cut down, ceased or drastically reduced: the number of new cases of HIV among injecting drug users has increased since 2010, as well as reports of increased influenza mortality, appearance and spread of the West Nile virus, and emerge of endemic malaria (Bonovas \& Nikolopoulos 2012).

The current study explores, for the first time in Greece, the health status and the socio-economic characteristics of all uninsured persons who obtained a medical cover book for uninsured citizens upon their request at the Social Services of one of the biggest Municipalities in Attica region. The study was based on processing data from official government documents, covering the period 2012-2016, which is within the core of the economic crisis in Greece, and aims to contribute in the broad scientific debate on the relationship between austerity policies in times of economic crisis and inequalities in social protection 


\section{RESEARCH ARTICLES}

and health for members of the most vulnerable groups of the population. By identifying health status and demographic, economic and social characteristics of uninsured citizens in a large municipality and exploring risk factors such as long-term unemployment, low income and housing status, health and chronic illness management, the current study further aims to provide an evidence-based ground for developing protective policies and implementation of targeted actions to protect vulnerable population groups.

\section{METHODS}

The Municipality

The Municipality of reference belongs to the Region of Attica, which was particularly affected by the economic crisis, showing a high unemployment $(28.2 \%$ in 2014 , while the corresponding national rate was $27.13 \%$ ) and long-term unemployment rates: $68.8 \%$ were long-term unemployed for more than 12 months (Attica Region 2015). The Municipality is ranked 17th in the relevant table of the linear indicator of human poverty, among 66 Municipalities (Attica Region 2015). It was one of the first to apply and exercise the responsibility to issue health insurance cover books for uninsured citizens in accordance with the legislation in force. As a result, the Department of Social Services of the Municipality has a complete and large volume of database regarding health status of uninsured citizens, covering a 4 years period of time (2012-2016).

\section{Population}

The study population comprises the total number of uninsured citizens $(\mathrm{N}=1,738)$ who applied for, and obtained, a health care cover book for uninsured citizens, by the Social Service of the Municipality, from 19-5-2012 to 4-4-2016, according to the legislation in force. This is a period of almost four years, amid a period of economic crisis, which is bounded by the opening date of the Insurance Office for Unsecured Citizenship, at the Social Solidarity Department of the Municipality and the date that this service was abolished, as the State provided access to public health services for all uninsured citizens by using only their Social Security Number.

In accordance with the legislation laying down the conditions, criteria and procedures for issuing a medical cover book for uninsured and financially weak citizens, which was in force at the time of the survey, a Special Social Assistance Committee is being set up in the Social Services Directorate of each Municipality, which examines the applications request interested parties. Beneficiaries, who are legally and permanently resident of the country, are Greek citizens or Greeks of Greek origin (expatriates holders of an expatriate identity card) or stateless persons or nationals of the European Union Member States are uninsured. Furthermore, their annual family income does not exceed the amount of 6.000 Euros, increased by $20 \%$ for the spouse and for each minor or protected child, provided, that such income does not come from a professional activity that enables him/her to be insured This fixed income is increased by $50 \%$ in the case of persons with a $67 \%$ or more disability. Income is the actual or imputed taxable income, including tax-excempt. Beneficiaries have free of charge access to examination, medication (from a specific list), paraclinical or laboratory examinations and full hospitalization, only in the NHS hospitals. Every single uninsured citizen possessed a unique number in the Municipality's electronic welfare Record; this was the only criterion for participating in the study.

\section{Study design - Procedure}

For the collection of all available economic, demographic, social and health-related data, 1,738 e-Registries of uninsured citizens were systematically explored. In addition, as the existing data in the e-Registry were considered inadequate, every individual folder was further investigated by the primary researcher (SK), who collected data such as citizens' gender, date of birth, nationality, actual annual income, unemployment and residence status, disability and disease categories.

As a result of the above procedure, a new database was created, unifying the existing fields of the electronic Registry with the following new data: gender, age, citizenship, unemployment status, residence status (rented house, owned house, guest), real annual income (declared to the tax office), type of disease (chronic or acute) disease and categories of disease.

In order to accurately mirror the characteristics of the studied population and facilitate data processing, the research team grouped gathered information into five main categories - participant's profiles. The common characteristic of all profiles was citizens' non-insurance coverage, while the individual attribute for each of the five profile categories was:

a / long-term (>12 months) unemployment, for the unemployed;

b / the certified disability of more than $67 \%$, for disabled citizens;

$c /$ being under 18 years old, for the minors;

$d /$ the use of substances, for drug users;

e / HIV seropositivity, for seropositive.

The study took place from October 2016 to January 2017.

Statistical analysis 
RESEARCH ARTICLES

Using Stata 11.0, we produced descriptive tables for all beneficiaries, both for their demographic and socio - economic characteristics, focusing mainly on gender, age, income and housing status, as well as their health status, which was determined by two basic values: the existence of a disease or not. In a second stage, possible correlations and differences in rates were explored, focusing on the group of uninsured citizens who had been diagnosed with a chronic disease.

Chi-square test was used for hypothesis testing setting the alpha level at 0.05 . Univariable and multivariable analyses using logistic regression were performed in order to examine possible associations between population characteristics and suffering from a chronic health condition. Annual income was not used in the model, because there were different income limits for the acquisition of the uninsured citizen cover book for people with and without a chronic disease, so adding outcome into the model would produce a false negative association between income and chronic disease.

\section{Ethical considerations}

The study concerned the processing of data already collected by a public body. In order to carry out the study, permission to access data was asked and granted by both the Municipality and the Department of Social Services, in which both the electronic Registry and the beneficiaries' personal files were kept and registered.

As the study included the collection of data for individuals whose identity could be recognized, its design ensured that the data were kept confidential. More specifically, data collection and recording took place within the physical space of the Department of Social Services, where the personal files were kept. Only the primary researcher (SK) and the employees of the Department, appointed for data registration and management were physically present. No individual file was moved outside the room. The primary investigator ensured the secure storage of the collected data in a database on his personal computer with the use of a secret password, and exclusive access to them by himself, as no access authorization was given to any other person. During processing, data was converted into unidentifiable personal - unidentifiable anonymized data, removing any data that could be used to identify participants when analyzing or publishing the study results.

\section{RESULTS}

Table 1 shows the basic demographic and socioeconomic characteristics of all participants. The majority of non-insured persons were 35-64 years old (61.7\%), of Greek citizenship (96.9\%), women (54.4\%), while
Table 1. Characteristics of the study population $(N=1,738)$

\begin{tabular}{|c|c|c|}
\hline & $\mathrm{n} / \mathrm{N}$ & $\%(95 \% \mathrm{Cl}]$ \\
\hline \multicolumn{3}{|l|}{ Gender } \\
\hline Male & $789 / 1730$ & $45.6(43.3-48.0)$ \\
\hline Female & $941 / 1730$ & $54.4(52.0-56.7)$ \\
\hline \multicolumn{3}{|l|}{ Age } \\
\hline$<18$ & $255 / 1724$ & $14.8(13.2-16.5)$ \\
\hline $18-24$ & $81 / 1724$ & $4.7(3.8-5.8)$ \\
\hline $25-34$ & $175 / 1724$ & $10.2(8.8-11.7)$ \\
\hline $35-44$ & $352 / 1724$ & $20.4(18.6-22.4)$ \\
\hline $45-54$ & $337 / 1724$ & 19.5 (17.7-21.5) \\
\hline $55-64$ & $375 / 1724$ & $21.8(20.0-23.8)$ \\
\hline $65-74$ & $142 / 1724$ & $8.2(7.0-9.6)$ \\
\hline $75+$ & $7 / 1724$ & $0.4(0.2-0.8)$ \\
\hline \multicolumn{3}{|l|}{ Ethnicity } \\
\hline Greek & $1675 / 1729$ & $96.9(95.9-97.6)$ \\
\hline non-Greek & $54 / 1729$ & $3.1(2.4-4.1)$ \\
\hline \multicolumn{3}{|l|}{ Profile Category } \\
\hline Drug user & $56 / 1738$ & $3.2(2.5-4.2)$ \\
\hline Disabled & $380 / 1738$ & $21.9(20.0-23.9)$ \\
\hline Unemployed/Uninsured & $1001 / 1738$ & $57.6(55.2-59.9)$ \\
\hline Minor & $292 / 1738$ & $16.8(15.1-18.6)$ \\
\hline HIV seropositive & 9/1738 & $0.5(0.3-0.9)$ \\
\hline \multicolumn{3}{|l|}{ Disease } \\
\hline Chronic & $725 / 1738$ & $41.7(39.4-44.0)$ \\
\hline Acute & $82 / 1738$ & $4.7(3.8-5.8)$ \\
\hline Not stated & $931 / 1738$ & $53.6(51.2-55.9)$ \\
\hline \multicolumn{3}{|l|}{ Housing status } \\
\hline Owned house & $337 / 1685$ & $20.0(18.2-22.0)$ \\
\hline Rented house & $243 / 1685$ & $14.4(12.8-16.2)$ \\
\hline Guest & $392 / 1685$ & $22.6(20.6-24.6)$ \\
\hline $\begin{array}{l}\text { Guest in parents'/ } \\
\text { offsprings' house }\end{array}$ & $465 / 1685$ & 26.7 (24.7-28.9) \\
\hline Minor (n/a) & $248 / 1685$ & $14.7(13.1-16.5)$ \\
\hline \multicolumn{3}{|l|}{ Annual income (in euro) } \\
\hline 0 & $1200 / 1738$ & $69.0(66.8-71.2)$ \\
\hline$<3000$ & $145 / 1738$ & $8.3(7.1-9.7)$ \\
\hline $3000-5000$ & $310 / 1738$ & $17.8(16.1-19.7)$ \\
\hline$>5000$ & $83 / 1738$ & $4.8(3.9-5.9)$ \\
\hline \multicolumn{3}{|l|}{ Renewals } \\
\hline 0 & $822 / 1730$ & $47.5(45.2-49.9)$ \\
\hline 1 & $383 / 1730$ & $22.1(20.2-24.2)$ \\
\hline
\end{tabular}




\section{RESEARCH ARTICLES}

Table 1. Characteristics of the study population $(\mathrm{N}=1,738)$ (ouvéxદıa)

\begin{tabular}{|c|c|c|}
\hline & $n / N$ & $\%(95 \%$ Cl) \\
\hline 2 & $264 / 1730$ & $15.3(13.6-17.0)$ \\
\hline 3 & $229 / 1730$ & $13.2(11.7-14.9)$ \\
\hline 4 & $32 / 1730$ & $1.8(1.3-2.6)$ \\
\hline & Mean & SD \\
\hline Age & 42.08 & 18.29 \\
\hline
\end{tabular}

Table 2. Registrations by year and profile category

\begin{tabular}{|c|c|c|c|c|c|c|c|c|c|c|c|}
\hline \multirow{2}{*}{$\begin{array}{l}\text { Profile } \\
\text { Category }\end{array}$} & \multicolumn{2}{|c|}{ Drug user } & \multicolumn{2}{|c|}{ Disabled } & \multicolumn{2}{|c|}{ Unemployed/Uninsured| } & \multicolumn{2}{|c|}{ Minor } & \multicolumn{2}{|c|}{ HIV seropositive } & \multirow{2}{*}{$\frac{\text { Total }}{\mathbf{N}}$} \\
\hline & $\bar{n}$ & $\%$ & $\mathbf{n}$ & $\%$ & $n$ & $\%$ & $\mathbf{n}$ & $\%$ & $n$ & $\%$ & \\
\hline $\begin{array}{l}\text { Year of } \\
\text { registration }\end{array}$ & & & & & & & & & & & \\
\hline 2012 & 19 & 3.8 & 182 & 36.2 & 232 & 46.2 & 64 & 12.8 & 5 & 1.0 & 502 \\
\hline 2013 & 27 & 6.4 & 107 & 25.5 & 214 & 51.1 & 69 & 16.5 & 2 & 0.5 & 419 \\
\hline 2014 & 4 & 1.1 & 56 & 15.6 & 235 & 65.6 & 62 & 17.3 & 1 & 0,3 & 358 \\
\hline 2015 & 3 & 0.9 & 28 & 8.3 & 233 & 69.3 & 71 & 21.1 & 1 & 0.3 & 336 \\
\hline $2016^{*}$ & 3 & 2.6 & 7 & 6.1 & 84 & 73.0 & 21 & 18.3 & 0 & - & 115 \\
\hline
\end{tabular}

the largest percentage were unemployed uninsured $(57.6 \%)$. Regarding health status, for about half of the participants $(53.6 \%)$ there was no registered official document certifying a health problem. Of the total uninsured citizens, $41.7 \%$ were recorded with a chronic disease. Regarding the socio-economic situation of the study population, a high percentage $(69.0 \%)$ had zero annual income, while almost half of them (50.9\%) were hosted by a relative or acquaintance.

Table 2 presents the registrations by year and profile category. As seen, there is a downward trend in total new registrations per year, while a significant upward trend in the category of unemployed is observed.

Table 3 presents the basic demographic and socioeconomic characteristics of only those with a chronic disease. A higher proportion (29.1\%) of chronically ill is observed within the "55-64" age group, compared to other age groups. Mental illness (37.8\%) prevailed, followed by cardiovascular disease (13.9\%). These two diseases, as well as cancer and diabetes, accounted for $67.7 \%$ of all chronically sufferers. Almost half $(48 \%)$ of uninsured patients with a chronic disease were registered with zero real annual income, while a high percentage $(60.4 \%)$ were registered as guests, half of them $(30.2 \%)$ from the family environment and the other half of an acquaintance.
Table 3. Characteristics of people with a chronic disease $(\mathrm{N}=725)$

\begin{tabular}{|l|c|c|}
\hline \multicolumn{1}{|l|}{ Gender } & n & \% (95\% Cl) \\
\hline Male & 360 & $49.7(46.0-53.3)$ \\
\hline Female & 365 & $50.3(46.7-54.0)$ \\
\hline Age & & \\
\hline$<18$ & 21 & $2.9(1.9-4.4)$ \\
\hline $18-24$ & 18 & $2.5(1.6-3.9)$ \\
\hline $25-34$ & 68 & $9.4(7.5-11.7)$ \\
\hline $35-44$ & 144 & $19.9(17.1-22.9)$ \\
\hline $45-54$ & 162 & $22.3(19.5-25.5)$ \\
\hline $55-64$ & 211 & $29.1(25.9-32.5)$ \\
\hline $65-74$ & 95 & $13.1(10.8-15.8)$ \\
\hline $75+$ & 5 & $0.7(0.3-1.6)$ \\
\hline Missing & 1 & $0.1(0.0-0.8)$ \\
\hline Ethnicity & & \\
\hline Greek & 712 & $98.2(97.0-98.9)$ \\
\hline non-Greek & 13 & $1.8(1.1-3.0)$ \\
\hline Profile Category & 378 & $52.1(48.5-55.8)$ \\
\hline Disabled & & \\
\hline
\end{tabular}


Table 3. Characteristics of people with a chronic disease $(\mathrm{N}=725)$ (ouvéxદıa)

\begin{tabular}{|c|c|c|}
\hline & n & $\%(95 \% \mathrm{Cl})$ \\
\hline Unemployed/ Uninsured & 276 & $38.1(34.6-41.7)$ \\
\hline Minor & 25 & $3.4(2.3-5.0)$ \\
\hline HIV seropositive/ Drug user & 46 & $6.3(4.8-8.4)$ \\
\hline \multicolumn{3}{|l|}{ Housing status } \\
\hline Owned house & 160 & $22.1(19.2-25.2)$ \\
\hline Rented house & 94 & $13.0(10.7-15.6)$ \\
\hline Guest & 219 & $30.2(27.0-33.6)$ \\
\hline $\begin{array}{l}\text { Guest in parents'/ } \\
\text { offsprings' house }\end{array}$ & 219 & $30.2(27.0-33.6)$ \\
\hline Minor (n/a) & 20 & $2.8(1.8-4.2)$ \\
\hline missing & 13 & $1.8(1.0-3.1)$ \\
\hline \multicolumn{3}{|l|}{ Renewals } \\
\hline 0 & 238 & 32.8 (29.5-36.3) \\
\hline 1 & 158 & $21.8(18.9-24.9)$ \\
\hline 2 & 138 & $19.0(16.3-22.1)$ \\
\hline 3 & 170 & $23.4(20.5-26.7)$ \\
\hline 4 & 21 & $2.9(1.9-4.4)$ \\
\hline \multicolumn{3}{|l|}{ Annual income (in euro) } \\
\hline 0 & 348 & $48.0(44.4-51.6)$ \\
\hline$<3000$ & 49 & $6.8(5.1-8.8)$ \\
\hline $3000-5000$ & 270 & $37.2(33.8-40.8)$ \\
\hline$>5000$ & 58 & $8.0(6.2-10.2)$ \\
\hline \multicolumn{3}{|l|}{ Chronic disease category } \\
\hline Cardiovascular & 101 & $13.9(11.6-16.7)$ \\
\hline Cancer & 55 & $7.6(5.9-9.8)$ \\
\hline Mental illness & 274 & $37.8(34.3-41.4)$ \\
\hline Diabetes & 54 & $7.4(5.7-9.6)$ \\
\hline \multirow[t]{2}{*}{ Other } & 241 & $33.2(29.9-36.8)$ \\
\hline & Mean & SD \\
\hline Age & 49.49 & 14.06 \\
\hline
\end{tabular}

Table 4 shows the correlation of gender, citizenship, housing and zero income of uninsured people with the four most prevalent chronic diseases: mental illness, cardiovascular, diabetes and cancer. People with mental illness were living as guests at a higher rate $(71.0 \%, p=0.002)$, compared to people suffering from the other diseases. Patients with cancer showed higher rates $(72.7 \%, p<0.001)$ of zero annual income, compared to the other diseases.

Table 5 shows the results of the univariable and multivariable logistic regression analysis. Age, gender, ethnicity, housing status and number of renewals of the uninsured citizen booklet were included as independent variables. According to the full model, one year increase in age was associated with a $3 \%$ increase in the odds of having a chronic disease. In addition, men had 1.7 times the odds of having a chronic disease, compared to women. Furthermore, suffering from a chronic condition was associated with more renewals of the uninsured citizen booklet. Moreover, people living as guests in a friend's or acquaintance's house had 1.5 times the odds of having a chronic disease, compared to people living in a rented or owned house. However, ethnicity showed no statistically significant association with chronic disease.

\section{DISCUSSION}

According to the results of the study a significant proportion of the surveyed population of uninsured citizens suffers from a chronic disease. Half of the chronic patients appear to live with zero annual income and a high rate of them lived as guests to friends or relatives. Mental illness is prevalent - with diabetes and cancer being followed - and is highly related to the status of guest. Male gender, age, and host status are related to the existence of chronic disease.

Based on the categorization of the population within the five basic profiles, the majority of the 1,738 uninsured citizens belonged to the group of unemployed uninsured, followed by the disabled people and the minors. Our findings are in line with those in the relevant literature, according to which young people, children, the unemployed and people with disabilities are among the most affected in times of economic crisis (European Commission 2017).

A high proportion of uninsured individuals were between the ages of 35 and 64 , while $71 \%$ were people aged 18 to 54 years, a potentially active workforce that is outside work, social security and medical coverage. These findings are in line with those of the Labor Force Survey in Greece from 1981 to 2015 for the general population (HSA 2017) and confirm that the economic crisis afflicts people of productive age and individuals 


\section{RESEARCH ARTICLES}

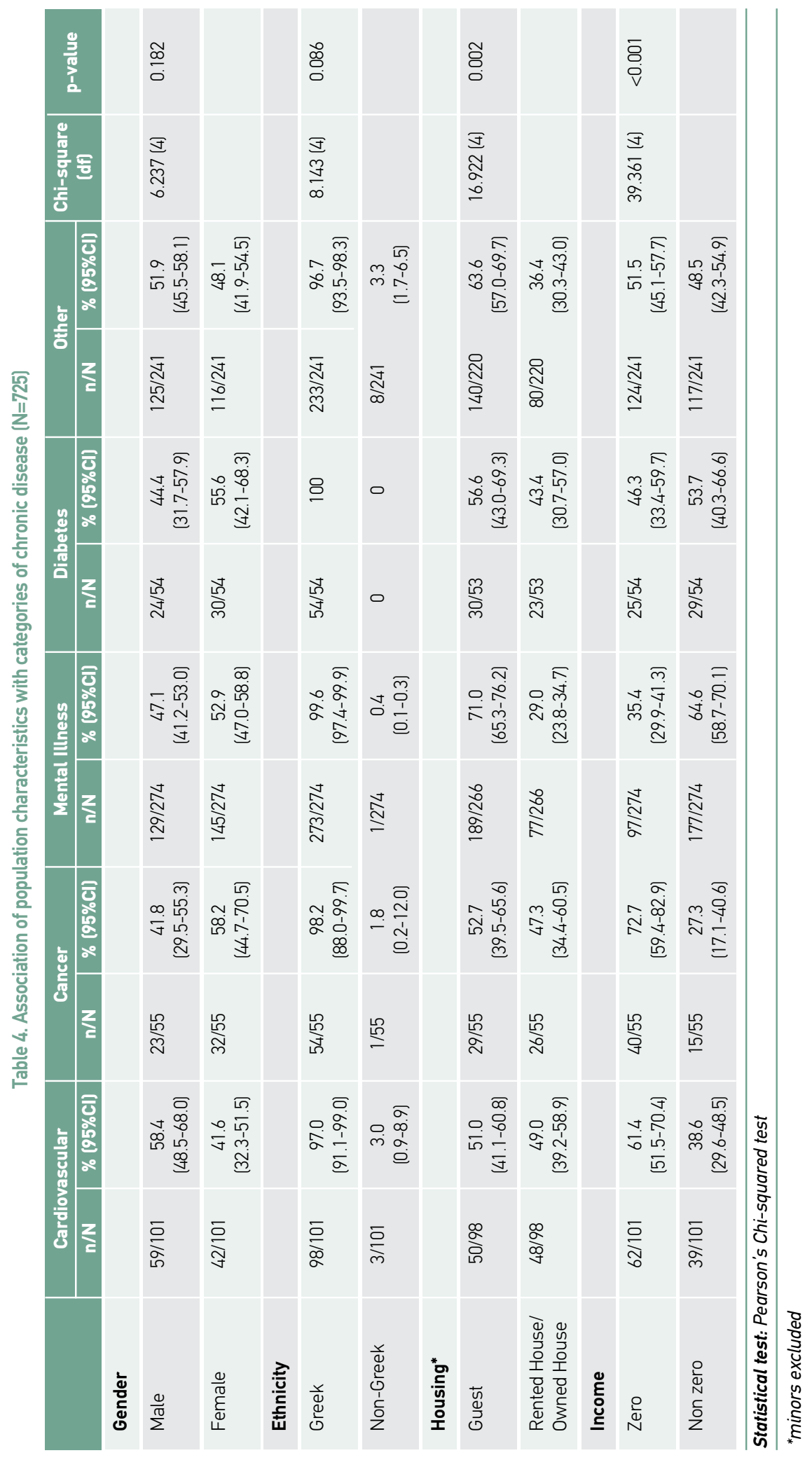


RESEARCH ARTICLES

Table 5: Univariable and multivariable analysis of population characteristics associated with chronic disease ( $\left.\mathrm{N}=1425^{*}\right)$

\begin{tabular}{|c|c|c|c|c|c|c|}
\hline & \multicolumn{2}{|c|}{ Chronic Disease } & \multirow[b]{2}{*}{ Crude OR } & \multirow{2}{*}{$\begin{array}{l}\text { OR adjusted for } \\
\text { age, gender }\end{array}$} & \multirow[b]{2}{*}{ OR Full model } & \multirow[b]{2}{*}{ p-value } \\
\hline & $\begin{array}{c}\text { Yes }(N=691] \\
n[\%]\end{array}$ & $\begin{array}{c}\text { No }(\mathrm{N}=734] \\
n[\%]\end{array}$ & & & & \\
\hline \multicolumn{7}{|l|}{ Age } \\
\hline Mean (SD) & $50.6(12.7)$ & $45.6(13.0)$ & $1.03(1.02-1.04)$ & $1.03(1.02-1.04)$ & $1.03(1.02-1.04)$ & $<0.001$ \\
\hline \multicolumn{7}{|l|}{ Sex } \\
\hline Female & 347 (43.9) & $444(56.1)$ & 1.00 (ref) & 1.00 (ref) & 1.00 (ref) & \\
\hline Male & 344 (54.3) & $290(45.7)$ & $1.52(1.23-1.87)$ & 1.59 (1.28-1.97) & $1.70(1.35-2.13)$ & $<0.001$ \\
\hline \multicolumn{7}{|l|}{ Renewal } \\
\hline 0 & 227 (34.3) & 435 (65.7) & 1.00 (ref) & 1.00 (ref) & 1.00 (ref) & \\
\hline 1 & $146(47.7)$ & 160 (52.3) & $1.75(1.33-2.30)$ & $1.75(1.32-2.31)$ & 1.73 (1.30-2.29) & $<0.001$ \\
\hline 2 & 131 (61.2) & $83(38.8)$ & $3.02(2.20-4.16)$ & $2.88(2.08-3.99)$ & $2.73(1.97-3.79)$ & $<0.001$ \\
\hline 3 & 166 (78.3) & $46(21.7)$ & 6.91 (4.81-9.95) & 6.57 (4.53-9.53) & $6.49(4.46-9.44)$ & $<0.001$ \\
\hline 4 & 21 (67.7) & 10 (32.3) & $4.02(1.86-8.69)$ & $4.18(1.91-9.11)$ & 3.79 (1.73-8.28) & 0.001 \\
\hline \multicolumn{7}{|l|}{ Ethnicity } \\
\hline Non-Greek & 13 (33.3) & $26(66.7)$ & 1.00 (ref) & 1.00 (ref) & 1.00 (ref) & \\
\hline Greek & $678(48.9)$ & $708(51.1)$ & $1.91(0.98-3.76)$ & $1.70(0.86-3.39)$ & $1.18(0.58-2.40)$ & 0.649 \\
\hline \multicolumn{7}{|l|}{ Housing status } \\
\hline Rented/ owned house & $254(43.8)$ & $326(56.2)$ & 1.00 (ref) & 1.00 (ref) & 1.00 (ref) & \\
\hline Guest & 437 (51.7) & 408 (48.3) & $1.37(1.11-.1 .70)$ & $1.68(1.34-2.11)$ & $1.57(1.24-2.00)$ & $<0.001$ \\
\hline
\end{tabular}

*minors excluded

before the age of retirement, as a consequence of the large number of redundancies. By monitoring the new registrations per year it is noted that while they are reduced overall, those of the unemployed are increasing significantly. In the current study, people whose unemployment lasted more than 12 months mostly belonged in the unemployed profile. The more the economic crisis lasts, the more the long-term unemployment is increased: and the longer one is out of the labor market, the more difficult is to come back, this is because the acquired work experience is lost over time, de-specialization comes and the potential recruitment turns to be even more difficult.

Regarding health status of the participants in the current study, $41.7 \%$ had a chronic disease. Only a small percentage (4.7\%) had been acutely ill, with respiratory infections, fractures, minor injuries, while parturitions. For $53.6 \%$ of the uninsured citizens, there was no official document (i.e. a diagnosis by a state physician, a Disability Certification Center report) regarding a health problem.

Reliable data on chronic morbidity rates in Greece are scarce. According to the Greek Health Survey data for the year 2014 (HSA 2016), one in two (49.7\%) aged 15 years and over, states that he/she has a chronic problem or chronic disease, while according to the results of the Hydria project, a survey of population health, in 20132014 , three in five adults (59.6\%) reported suffering from a chronic disease in 2014 (Hellenic Foundation of Health - HFH 2015).

By focusing on the group of the 725 uninsured citizens with a chronic illness, its prevalence was higher in the "55-64" age group. According to the Greek Health Survey data (HSA 2016), from all those claiming to have a chronic health problem or a chronic disease, six out of ten $(61.4 \%)$ were older than 55 years of age. On the other hand, a chronic disease is reported by more women (54.1\%) than men (44.8\%), in HSA (2016) Health Survey, which is not confirmed by our study.

The imprint of the current study is considered to be the association between economic situation and housing status of the uninsured participants with the existence of a chronic illness: it was found that almost one in two noninsured persons with chronic illness (48\%) was called to deal with the management of their chronic problem (i.e. medical visits, taking medication, examinations, etc.) having zero annual income. Additionally, almost two out of three participants of the same category $(60.4 \%)$ would 


\section{RESEARCH ARTICLES}

face the risk of homelessness in the case that no relative or acquaintance was available to house them. These high percentages of individuals with minimal or zero annual income, who at the same time live in precarious housing conditions, reflect the real dimensions of the unfavorable socio-economic situation of uninsured people, which a prolonged period of economic crisis can only worsen, according to the relevant literature (Adam \& Teloni 2015, Labor Institute of the Greek General Confederation of Labor 2017).

The current economic crisis seems to have led segments of the population already at high risk of poverty before the crisis, to an even worse situation. Income inequality has significantly been increased since the crisis (OECD 2017) in countries such as Greece, Italy and Spain, the United States which were affected more, as well as countries with a high level of inequality even before the crisis (e.g. Chile, Latvia). In 2012-2016, income inequality in Greece remained at a high level, with the uneven distribution of income (Gini coefficient) being raised from $34.2 \%$ to $34.5 \%$. Based on this coefficient, Greece is among the countries with the highest levels of income inequality in the EU (HSA 2018) along with Bulgaria, Romania and Latvia.

One of the main barriers to health services accessibility is the inadequacy of the necessary financial resources to cover the cost of such services [OECD 2009]. Low income, let alone zero, implies less access to both high-level preventive and therapeutic health services. Additionally, studies have showed that people living in poverty and social exclusion have higher rates of chronic health problems, as well as higher rates of constraint on their day-to-day activities due to some health problems than non-poor individuals (Mackenbach 2005).

The Health Survey for 2014 (HSA 2016) has showed that $13.9 \%$ of the population aged more than 15 years faced unmet needs for receiving medical care or treatment, due to financial inability, $15.4 \%$ for dental care or treatment, $4.3 \%$ for mental health care, and $11.2 \%$ for taking the medications prescribed by the physician. Non satisfaction of medical and pharmaceutical needs due to economic problems has also been confirmed in subsequent research (Kentikelenis et al 2014, DIANEOSIS 2016).

What was found in the current study for the Municipality of reference is similar to research done for Attica Region: since the beginning of the crisis the population living in precarious housing in Athens has doubled (Arapoglou et al 2015). This increase is due to the rapid rise in poverty and unemployment and the inability of households to cover housing costs, particularly rents, leading to crowding in small-scale housing, and the inappropriateness of housing.

Research has showed that inferior housing and deprived neighborhoods are associated with higher rates of child mortality, HIV, STDs, diabetes, cardiovascular diseases and violent deaths (Stuckler \& Basu 2014). Additionally, those experiencing housing hardship have high levels of stress, delayed visits to doctors since they are unable to cover the costs of examinations and treatment, and present low health levels (Stahre et al 2015). This is in line with our finding that guest status is associated with chronic disease.

Regarding guest status in housing, the findings of our study confirm the important role of the family and the broader social environment of individuals in Greece. These do not just function as ancillary to the state, but they essentially replace it, within a model of social protection in Greece which is characterized by an unequal distribution of social protection structures against social risks and poor quality of services (Yfantopoulos et al 2009). Within the midst of economic crisis, the high unemployment, and the increased number of those in precarious housing situation, state social welfare housing provision system both in the form of social housing provision and of rent subsidy or hosting hostels was, and still remains a deficit. On the contrary, the main parameters of housing policy after 2008 seem to "contribute to the generalization of housing insecurity, both at a financial level, by reducing the public expenditure on housing and overcrowding of the private dwelling, and an institutional level, with the abolition of the public Social Housing Agency" (Papadatos - Anagnostopoulos et al 2017, p. 39).

According to the results, mental illness prevails among the uninsured, followed by the cardiovascular disease. These two conditions, together with cancer and diabetes, accounted for $66.7 \%$ of all chronically patients of the study. Women showed a higher rate of psychiatric diseases, cancer and diabetes, while men have a higher rate of cardiovascular disease. Health Survey study for 2014 (HSA 2016) indicated that $9.2 \%$ of the population older than 15 years suffered from diabetes, with older women to take precedence over men, as in the present study, and $21 \%$ of the population reported hypertension. For the same year, the Hydria project showed prevalence rates for diabetes at $11.4 \%$ and acute myocardial infarction at $3 \%$ of the population, with more women suffering from diabetes than men and the converse for acute myocardial infarction (Hydria 2015). Results of the National Morbidity and Risk Factors Study, conducted by the Department of Medicine of the National and Kapodistrian University of Athens (NKUOA) (2015), showed that coronary artery disease was twice as common in men (6.3\%) than in women 
(3.1\%), while hypertension and cholesterolemia were more common. Additionally, $12.5 \%$ of men and $10 \%$ of women had diabetes ( $11 \%$ total).

The impact of the economic recession on mental health has been confirmed by a number of studies. The reported prevalence of chronic depression is $7.4 \%$ according to the HFH (2015) while according to the National Morbidity and Risk factors study (2015), stress symptoms and depression were reported by $24 \%$ and $16 \%$ of the general population, respectively with these symptoms being significantly associated with unemployment. In a survey on mental health and its socio-class stratification (Zisi et al 2017), it was found a strong correlation of poor mental health with the ranks of unemployed, self-employed and unskilled, as well as with low educational level and poor economic situation.

People with mental illness are at a higher risk of becoming unemployed in times of economic recession, while there is an increase in suicides between men and those in productive age affected by rising unemployment (Evans-Lacko et al 2013). This indicates that in times of economic crisis, there is a higher prevalence of people with mental illnesses in the unemployed population and a greater risk of their mental health deteriorating.

The high incidence of chronic psychiatric disease among uninsured people in our study is consistent with the findings of a number of studies that have highlighted the high degree of correlation between economic crisis and the prevalence of mental disorders (Stuckler et al.2009, Gili et al 2013). Most researchers agree that the loss of work increases the risk of psychiatric disorders and their physical effects, while many studies converge on the assumption of a strong correlation between unemployment and an increase in depression and anxiety (Tsounis 2013).

Interestingly, the findings of the present study show the prevalence of guest status among uninsured patients with mental illness and the prevalence of zero annual income among uninsured patients with cancer. The former may be related to the particularities of mental illness in the functioning of patients suffering from mental illness and the need for constant support and care. The latter is likely to be the result of the related benefit policy, since cancer patients are forced to stay out of work or look for a long time to respond to the treatments, and no financial support is provided for them unless they are diagnosed with an invalidity rate of $67 \%$ or more, in the form of severe disability benefits, which concerns the last stages of the disease.

\section{Study limitations}

The main limitation of the current study was the fact that health-related documents lofficial medical diagnoses) did not exist in the all personal files of the participants. This has an implication on the conceptual clarification of the population and the subsequent interpretation of the results: uninsured citizens without a disease categorized as "unrecorded" in the relevant field cannot be considered a priori healthy, of course neither sick. Instead, they are part of the population under investigation, since there is no data on their state of health.

In addition, the complex social reality, especially during a period of intense social transformation of the Greek society due to the prolonged economic crisis, requires more complex methodologies than the one used in the current study; it requires the contribution of multidisciplinary approaches (triangulation) to ensure all conditions that lead to safe conclusions. For this reason, it is proposed to strengthen future research in the field using qualitative methods (such as conducting interviews) to study the underlying research phenomenon.

The results of our study cannot be generalized to the whole population of uninsured citizens either in the Municipality of reference or in Attica region, or extrapolated to other populations, as current study's population consisted of only the uninsured citizens who applied for and obtained a medical cover book, therefore a possible biased sample. Thus, the results of the current study can be used as an initial pilot, triggering for future studies among the population with corresponding characteristics, in other municipalities.

\section{CONCLUSIONS}

Fiscal Adjustment Programs in Greece have deteriorated the living conditions of the population, aggravating income inequalities, which also fuel inequalities in health. The current study in an Attica region Municipality showed that a significant percentage of uninsured citizens who have obtained an insurance book from Social Services of the Municipality during the period of the economic crisis, suffer from chronic illness and live with zero income hosted by relatives or acquaintances, which has a long-term impact on determinants of their health.

A series of direct interventions at the community level in the field of health and social protection are considered necessary and the findings of this our study can be used as a guide towards this direction. A redesign of primary health care and social protection at the Municipality level will allow citizens to have direct and total access to quality health care and social services is necessary.

In particular, for the issue of medical cover book and the relevant income criteria, there must be an explicit 


\section{RESEARCH ARTICLES}

exemption for all kinds of social benefits (eg subsistence allowance, disability allowance, etc.) and should be granted to certain categories of beneficiaries, as asylum seekers, migrants with residence documents, the homeless, the disabled of more than $67 \%$ disabillity, all categories of prisoners, victims of trafficking, pregnant women, sufferers of chronic or incurable diseases, people housed in treatment communities for detoxification, irrespective of income.

The systematic recording of data regarding the social and economic profile as well as health status of the community population, especially the vulnerable groups, highlights the real needs, as did the current study, and enables the implementation of small scale policy interventions for the local population, which bring immediate results. As such, it is proposed to strengthen employment policies with offering new jobs and reintegrate into work, support social housing and rent subsidies, adopt a holistic approach to caring for chronically ill people, support for the independent living of mental patients, and create home support units for cancer patients and pain management.

\section{Contribution of the authors}

SK: participated in the conception and planning of the study, data collection, interpretation of the results and writing of the article GK: participated in the planing of the study, interpretation of the results and writing of article IZ: participated in the data analysis, interpretation of the results and writing of the article. KO: participated in the conception of the study and writing of the article. All authors critically assessed and approved the submission of the final text.

\section{Conflict of interest}

Researchers state that there is no conflict of interest.

\section{REFERENCES}

Adam S. \& Teloni D. (2015). Social Clinics in Greece of Crisis: The Experience of Health Services When the National Health System Decreases, Studies 44, Observatory of Economic and Social Development, INE-GSEE, Athens. Available at: https:// ineobservatory.gr/wp-content/uploads/2016/07/MELETH-441.pdf [Accessed: 12 February 2018].

Arapoglou V., Gounis K. \& Siatitsa D. (2015). Revisiting the Concept of Shelterisation: Insights from Athens, Greece. European Journal of Homelessness 9: 137-157.

Attica Region (2015). Regional Strategy for Social Inclusion and Fight against Poverty, Study, Athens. Available at: http://www. pepattikis.gr/ wpcontent/uploads/2016/02 [Accessed: 20 January 2018].

Bonovas S. \& Nikolopoulos G. (2012). High-burden epidemics in Greece in the era of economic crisis. Early signs of a public health tragedy. Journal of Preventive Medicine and Hygiene 53: 169-71. doi:10.15167/2421-4248/jpmh2012.53.3.340.

Branas C., Kastanaki A., Michalodimitrakis M., Tzougas J., Kranioti E., Theodorakis P., Carr B. \& Wiebe D. (2015). The impact of economic austerity and prosperity events on suicide in Greece: a 30 year interrupted time-series analysis. BMJOpen 2015;5:e005619. doi :10.1136/bmjopen-2014-005619.

Department of Medicine NKUOA (2015). The Health Situation in Greece of 2015: Chronic Diseases - Access to the Health System - Prevention. National Morbidity and Risk Factors Study, National and Kapodistrian University of Athens, Athens. Available at: www. emeno.gr [Accessed: 6 February 2018].

Institute of Social and Preventive Medicine (2016). Health of Greeks in Crisis, Institute of Social and Preventive Medicine, Athens. Available at: https://www.dianeosis.org/research/greek_health/ [Accessed: 20 May 2018].

Economou Ch., Kaitelidou D., Kentikelenis Al., Sissouras A. \& Maresso A. (2014). The impact of the financial crisis on the health system and health in Greece, Case Study. World Health Organization, European Observatory on Health Systems and Policies. Available at: http://www.euro.who.int/_data/assets/pdf_file/0007/266380/ The-impact-of-the-financial-crisis-on-the-health-system-andhealth-in-Greece.pdf [Accessed: 10 May 2018].

European Commission (2017). Joint Employment Report 2017 accompanying the Communication from the Commissionon on the Annual Growth Survey 2017, Brussels Available at: https:// ec.europa.eu/social/main.jsp?advSearchKey=joint+employment + report\&mode $=$ advancedSubmit\&catld $=22 \&$ policyArea $=0 \&$ polic yAreaSub $=0 \&$ country $=0 \&$ year $=0$ [Accessed: 5 May 2018].

Evans-Lacko S., Knapp M., McCrone P., Thornicroft G. \& Mojtabai R. (2013). The mental health consequences of the recession: economic hardship and employment of people with mental health problems in 27 European countries.PloS One 8: e69792. doi:10.1371/journal.pone.0069792.

Gili M., Roca M., Basu S., McKee M. \& Stuckler D. (2013). The mental health risks of economic crisis in Spain: evidence from primary care centres, 2006 and 2010.The European Journal of Public Health 23: 103-108. doi: 10.1093/eurpub/cks035.

Hellenic Foundation for Health (2015). HYDRIA Program: ConclusionsRemarks and Proposals for Policy Measures. Available at: http:// www.hhf-greece.gr/images/book-hydria-120516print.pdf [Accessed: 10 June 2018].

Hellenic Statistical Authority - HSA (2016). Health Survey: Year 2014, Hellenic Statistical Authority, Piraeus.

Hellenic Statistical Authority - HSA (2017). Labor Force Survey: 19812015, Hellenic Statistical Authority, Piraeus.

Hellenic Statistical Authority - HSA (2018). Economic Imbalance - Income Survey and Household Living Survey 2017, Hellenic Stastical Authority, Press Release, June, Piraeus. Available at: http://www.statistics.gr/documents/20181/f925863c-8396-4f7aa9dc-d4ef77883f73 [Accessed: 25 June 2018].

Kentikelenis A., Karanikolos M., Reeves A., Mckee M. \& Stuckler D. (2014). Greece's health crisis: from austerity to denialism. The Lancet 383: 748-53.doi: 10.1016/S0140-6736(13)62291-6

Kyriopoulos J. \& TsiantouV. (2010). The financial crisis and its impact 
on health and medical care. Archives of Hellenic Medicine 27: 834-840.

Labor Institute of Greek General Confederation of Labor (2017) The Greek economy and employment, Annual Report, Athens, March Available at: https://www.inegsee.gr/wpcontent/ uploads/2017/03/ETHSIA_EKTHESH_2017.pdf [Accessed: 25 May 2018].

Mackenbach J.P. (2005). Health Inequalities: Europe in profile. An Independent expert report commissioned by, and published under the auspices of, the UK Presidency of the EU. Available at: http://www.who.int/social_determinants/resources /european_ inequalities.pdf [Accessed: 10 Aprile 2018].

Marmot M. \& Bell R. (2009). How will the financial crisis affect health? $B M J, 338,858-860$. doi : 10.1136/bmj.b1314.

OECD (2009). Health at a Glance 2009, Indicators, OECD Publishing, Paris. doi.org/10.1787/19991312.

OECD (2017). How's Life? 2017: Measuring Well-being, OECD Publishing, Paris, doi.org/10.1787/how_life-2017-en.

Papadatos-Anagnostopoulos D., Seretis S., Poulimas M. \& Benos A. (2017) Management of Crisis, Housing and Health: Generalization and Measurement of Housing Risk and Health Safety in Greece. Social Policy 8: 21-49 doi:10.12681/sp.14603.

Simou E. \& Koutsogeorgou E. (2014) Effects of the economic crisis on health and healthcare in Greece in the literature from 2009 to 2013: A systematic review. Health Policy 115: 111-119.doi: 10.1016/j.healthpol.2014.02.002.

Solar 0. \& Irwin A. (2010). A conceptual framework for action on the social determinants of health. Social Determinants of Health Discussion Paper 2 (Policy and Practice), World Health Organization, Geneva.

Stahre M., VanEenwyk J., Siegel P. \& Njai R. (2015). Housing Insecurity and the AssociationWith Health Outcomes and Unhealthy Behaviors, Washington State, 2011. Preventing Chronic Disease 12:140511. doi : 10.5888/pcd12.140511.

Stuckler D. \& Basu S. (2014) Life and Death Policies, How does the crisis affect human health, Psihogios, Athens.

Stuckler D., Basu S., Suhrcke M., Coutts A. \& McKee M. (2009). The public health effect of economic crises and alternative policy responses in Europe: an empirical analysis. The Lancet 376: 315323. doi : 10.1016/S0140-6736(09)61124-7.

Tsounis A. (2013). The relationship of unemployment with depression and suicides: the "clinical" reflection of the economic crisis. Psychiatry NoteBooks 122: 24-32.

Yfantopoulos G., Balourdos K. \& Nikolopoulos K. (2009). Economic and Social Dimensions of the Welfare State, Gutenberg, Athens, pp. 76-80.

Zisi A., Stalidi G. \& Benos A. (2017) Social class and mental health: A comparative community study. Archives of Hellenic Medicine 34: $75-85$. 